\title{
Infancias, escuela y educación: una mirada (entre)generaciones
}

DOI: https://doi.org/10.32870/dse.v0i10.287

\section{Myriam Southwell*}

Un clásico dicho de uso corriente expresa que los hijos se parecen más a su tiempo que a sus padres. Con esa frase se quiere evidenciar que cada época imprimió características peculiares a los sujetos, confrontándolos con determinados problemas, con instituciones particulares, con tecnologías y modos de entender la cultura que los moldearon y los ayudaron a devenir adultos.

La escuela tuvo mucho que ver con la delimitación de la infancia, tanto por la difusión de un discurso psicológico que estableció de manera taxativa qué debía esperarse de los niños, como por la expansión de una idea de minoridad-incompletud-inmadurez que colocó a la infancia en un lugar subordinado, cuya voz y perspectivas no debían tenerse en cuenta. También tuvo mucho que ver con la producción de una infancia "correcta" y "aceptable" en términos morales y políticos. Una recorrida por los textos escolares, por ejemplo, nos permite ver los esfuerzos estatales para construir "un buen niño o niña": patriota, ejemplo ciudadano, moralmente medido y con pautas de higiene y con roles sociales claramente delimitados.

Más recientemente — pero sin reemplazar completamente lo mencionado anteriormente - tomamos cuenta de los cambios culturales y tecnológicos que tuvieron lugar en el último siglo, acelerados exponencialmente en las últimas décadas. La radio y la televisión fueron medios que rompieron con las jerarquías en el hogar, al pensar en una audiencia única que podía sentarse a ver y a escuchar lo mismo. Aun cuando hoy la segmentación de los públicos va en la dirección inversa (canales y sitios para cada gusto), hay algo sobre lo que no se retrocedió: los niños y jóvenes se comportan como sujetos con igual capacidad de decidir, de consumir y de ser objeto de discursos mediáticos como los adultos — aún cuando no lo sean totalmente- . Dueños del control remoto, están acostumbrados a formas de interacción que los colocan como pares, como soberanos, como sujetos a los que hay que conquistar y seducir.

¿Qué pedagogías necesita hoy esta infancia? ¿Qué políticas educativas son necesarias para atender sus necesidades, para protegerla y cuidarla y a la par ir dándole márgenes crecientes de autonomía? Son preguntas que todos los que estamos involucrados en la educación debemos tomar

* Es Ph.D. del Departamento de Gobierno de la Universidad de Essex, Inglaterra. Autora de diversos trabajos sobre temas de historia, teoría y política educacional. Actualmente es investigadora del CONICET y Titular de la cátedra Historia de la Educación Argentina y Latinoamericana de la Universidad Nacional de la Plata y Secretaria Académica de la FLACSO Sede Argentina. 
en serio, para que la escuela sea una experiencia relevante para la niñez de hoy, para ampliar sus márgenes de acción, sus recursos culturales y sus posibilidades de imaginarse como adultos plenos, con proyectos y con futuro.

Por otro lado, algo que siempre es motivo de debate y tensión en la educación de los más chicos es la relación entre juego y aprendizaje. Hay dos fenómenos: desde el conjunto del sistema educativo hay una mirada descalificadora del jugar, un cierto desprecio por lo que eso enseña, asociado, muchas veces, a la presión por contar con contenidos evaluables de manera sistemática. El otro fenómeno es que el espacio de juego está cada vez más atravesado por personajes ligados al mercado de consumo y la industria cultural (que vienen de la televisión, el cine o de la industria del juguete), y en general cuesta hacerle un lugar a la inventiva para una imaginación menos "guionada" y homogeneizada por estas figuras de consumo masivo. Lo que resulta cada vez más claro es que para educar a los chicos más pequeños no basta con dos o tres herramientas básicas, sino que es necesario un soporte conceptual que tenga en cuenta la complejidad y que resista la tentación de infantilizar un vínculo educativo que se dirige a la primera infancia, pero que pone a adultos en situaciones de gran responsabilidad. Casi podría decirse: cuanto más pequeños, más responsabilidad.

Quizás, entonces, la primera cuestión sea mantener un cierto "enigma" sobre lo que es y lo que puede la primera infancia, para que nuestros saberes no obstaculicen desarrollos y experiencias que pueden ser mucho más provechosos de lo que imaginamos. Deberíamos poder volver a mirar la infancia "con ojos de niño", con una curiosidad y una sorpresa renovadas. Como afirma Walter Kohan, hacer filosofía "entre" niños, para afirmar que "hay que pensar la infancia no como aquello que tenemos que formar sino que debemos abrirnos a lo que la infancia nos puede preguntar". La infancia son muchas cosas, pero ante todo es el mundo de los niños y sobre ellos debemos conservar "la condición de posibilidad" (Frigerio: 2006: 328). No "infantilizar" ese vínculo no quiere decir dejar de considerarlos niños, sino mantener una pregunta abierta y activa sobre la infancia.

\section{El vínculo intergeneracional como imperativo ético}

Las sociedades -en todo tiempo y lugar- parecen ser espacios en el que conviven distintas temporalidades, distintas maneras y experiencias de vivir el tiempo. A la escuela le ha tocado entre sus funciones ir un poco a contramano de esa vivencia en la construcción, enseñanza y sostén de una determinada temporalidad. ¿Ha sido eso incorrecto? No necesariamente, podríamos decir que esa ha sido una de las condiciones que la escuela debió crear para hacer su trabajo. Pero también podemos agregar que ese elemento de partida es una tensión permanente, y que hay modos distintos de posicionarse frente a ella, que se concretan en los modos cotidianos en los que ella toma forma. Se trata de un ejercicio cultural que abarca viejas y también inéditas características, un reconocimiento de la densidad del tiempo presente y de que el tiempo escolar convive con otros que lo tensionan y le exigen revisiones y reformulaciones. 
La educación se produce siempre en la brecha del tiempo, la transmisión se produce -consciente o inconscientemente- desde la densidad del presente, interrogando a la vez el pasado, herencias parciales, historias locales, identidades generales y particulares. La tarea sustantiva de la transmisión se vincula con el problema de las formas de filiación generacionales. Hay allí un trabajo de filiación que toma cuerpo en el sistema educativo de una manera más ostensible que en otros espacios; se trata de un trabajo de reconocimiento que al filiar reconoce, da lugar. Como sabemos, a la escuela no le ha tocado una tarea fácil ya que uno de los aspectos que se ha visto conmovido es la relación entre presente y futuro, el sentido de las postergaciones con miras al futuro, la movilidad social vivida de una generación a otra, dentro de las familias, etc. Ello genera una tensión entre distintas experiencias del tiempo, que han hecho estallar ese tiempo lineal del progreso en el proyecto de la instrucción pública moderna.

La infancia es un objeto discursivo, es decir, está moldeada por discursos diversos (científicos, psicológicos, médicos, pedagógicos, etc.; y también por discursos político-legales, por discursos morales, entre otros). Así, nuestra sensibilidad sobre la infancia ha resultado de una construcción social, producto de construcción larga, producto de diversos contextos culturales, científicos, pedagógicos. Producto de esa construcción de larga duración, preveemos, pensamos y proponemos determinadas maneras en las que se desarrolla la vida de los niños y niñas y sus formas de socialización. Me parece crucial enfatizar eso en un contexto en el que los lazos entre las generaciones se han conmovido y modificado enormemente.

Existen distintos tipos de infancia, y esto es un dato de la actualidad, pero también lo fue en su despliegue histórico, donde también los primeros años de vida se vivieron de manera muy heterogénea. Incluso en el clásico trabajo del historiador Philippe Ariès, que planteaba la emergencia del sentimiento de infancia en el siglo XVI y XVII, puede observarse que la infancia no existía de la misma manera para todos, y que las concepciones de infancia de los trabajadores no eran las mismas que las de los aristócratas. Esto nos permite pensar no sólo en los cambios históricos, sino también en las diversidades y disparidades actuales, por ejemplo en las disparidades entre regiones pero también en una misma localización. En el mundo globalizado hay que ver que estas diferentes infancias se relacionan de maneras complejas, por ejemplo, hay niños y niñas en talleres clandestinos de algún país que producen los bienes que consumen sus coetáneos con mayores posibilidades de consumo en otros países. Hay una multiplicidad de infancias, y también hay relaciones de explotación entre los diferentes tipos de infancia.

Para cerrar, permitanme apelar a un cuento infantil. "El emperador está desnudo... -gritó un niño-" nos relata el cuento de Hans Christian Andersen, revelando la presencia de un infante que denuncia aquello que la anuencia de los adultos que rodeaban al emperador no se atrevía a decir. La presencia de ese niño y lo que él pone en evidencia irrumpe y avergüenza a los adultos que se han convertido en cómplices, por no hacer evidente que su palabra era disonante de la del emperador y su séquito (Southwell, 2003). 
De modo similar, la infancia contemporánea, dentro y fuera de las escuelas, se convierte en el lugar de la enunciación de lo inconcluso, de las deudas sociales y de la exclusión del proyecto tecnocrático-modernizador con el que se cerró el arduo siglo XX. Su presencia silenciosa-y a veces a gritos- mostró la fragilidad de la pretensión del mercado como nuevo regulador de la participación de los ciudadanos, así como de la prédica de su potencialidad integradora.

Y el emperador se sintió inquieto, porque pensó que tenían razón, pero se dijo:

-Debo seguir en la procesión.

Y se irguió con mayor arrogancia y los chambelanes le siguieron portando la cola que no existía.

Si los niños denuncian con su presencia todo aquello que no ha sido logrado y toda la "tarea pendiente", nos resta -entre otras cosas- no naturalizar su ausencia en el patio escolar, su actitud de "buscavidas", sus modos de sobrevivir en las adversidades de distinto tipo. Ello posibilita el ejercicio de seguir buscando -de hecho, imaginando- posibilidades que sean alternativas. Esas alternativas pueden interpelar el sentido común acumulado en las escuelas, que espera que la niñez se exprese de determinadas maneras y se incomoda cuando se expresa de manera divergente. Encontrar maneras de alojar el enigma, de alejarse de la impugnación ante lo inesperado para constituirse en un lugar productivo de insistencia por el cuidado para los más chicos.

Los materiales para la elaboración probablemente ya esten aquí, a nuestro alrededor. También es seguro que no nos resulta productivo mirar a la infancia con una mirada nostálgica carente de memoria. Una sociedad que apuesta por su infancia es una sociedad que considera que tiene un legado valioso con el cual permanecer, pervivir y transmitir a los que vienen.

La escuela tienen el imperativo de poner en funcionamiento decisiones que pongan en acto los derechos y a hacerlos cotidianos, operando en las situaciones de conflicto, estableciendo acuerdos y mostrando las implicancias de las faltas de cuidado sobre los y las otro/as y sobre sí mismos. En esa búsqueda, la enseñanza de la reciprocidad y la mutua implicancia de nuestros actos pone a nuestras instituciones algunos pasos adelante para la vivencia de lo humano.

\section{Referencias}

Ariès, Philippe (1987). El niño y la vida familiar en el Antiguo Régimen. Madrid: Taurus.

Frigerio, Graciela (2006), "Infancias (apuntes sobre los sujetos)". En: Terigi, F. (comp.). Diez miradas sobre la escuela primaria. Buenos Aires: Siglo XXI.

Kohan, Walter (2007). Infancia, política y pensamiento: ensayos de filosofía y educación. Buenos Aires: del Estante Editorial.

Southwell, Myriam (2003). "El emperador está desnudo. Política, educación y modernización en los ‘90s”. En: VV.AA. Lo que queda de la escuela. Rosario: Laborde. 